\title{
Long-term effects of the cryopreservation of turbot (Psetta maxima) spermatozoa
}

\author{
Marc Suquet ${ }^{\left(1^{*}\right)}$, Catherine Dreanno ${ }^{(1-2)}$, Bruno Petton ${ }^{(1)}$, Yvon Normant ${ }^{(1)}$, \\ Marie-Hélène Omnes ${ }^{(1)}$, Roland Billard ${ }^{(2)}$ \\ (1) IFREMER, Laboratoire de Physiologie des Poissons, Centre de Brest, BP70, 29280 Plouzané, France. \\ (2) Muséum National d'Histoire Naturelle, Laboratoire d'Ichtyologie, 43 rue Cuvier, 75231 Paris, France.
}

Received November 19, 1997; accepted January 15, 1998

\begin{abstract}
The survival of turbot eggs and the rearing capacities of larvae stemmed from artificial fertilization practices using frozen-thawed spermatozoa were evaluated. Furthermore, the viability of sperm samples stored during a 9 month period in liquid nitrogen was assessed. No significant difference in the fertilization rate, hatching rate, survival and wet weight of 10 -day old larvae were observed using fresh or frozen-thawed spermatozoa. The motility recorded at $10 \mathrm{~s}$ and $60 \mathrm{~s}$ post-activation and the fertilization capacity of frozen-thawed spermatozoa were not significantly decreased during a 9 month storage period in liquid nitrogen. These results confirm the high quality of the turbot spermatozoa stemmed from the cryopreservation process, allowing their use for routine aquaculture practices. (C) Ifremer-Elsevier, Paris
\end{abstract}

turbot / Psetta maxima / sperm / cryopreservation / hatching

\section{INTRODUCTION}

Spermatozoa cryopreservation of more than 200 freshwater and marine fish species has been reported [17]. After freezing and thawing, sperm quality is most often assessed in terms of motility or fertilization capacity. However, the performances of fish produced using frozen sperm are rarely tested during subsequent rearing steps. Considerable ultrastructural alterations were observed in chromatin structure of rainbow trout and brown trout (Salmo trutta fario) thawed spermatozoa [3]. Such genome alterations could affect the embryonic development and survival of larvae. In a few fish species, the quality of offspring produced using frozen-thawed sperm was estimated for hatched

${ }^{(*)}$ Corresponding author (e-mail: msuquet@ifremer.fr) larvae (rainbow trout, Oncorhynchus mykiss [20]; striped bass, Morone saxatilis [9]; tilapia, Oreochromis sp. [4] and northern pike, Esox lucius [2] for 30day old larvae (tilapia [18]) or for 1-year old juveniles (channel catfish, Ictalurus punctatus [24]).

Most cryopreservation attempts delt with short freezing duration periods, generally ranging from $1 \mathrm{~h}$ up to 1 week. The storage time would not affect the results since the viability of gametes can be theoretically preserved between 200 and 32000 years [1]. However, the fertilization capacity of thawed spermatozoa of striped bass was suggested to be decreased in relation to the storage duration in liquid nitrogen [9].

A cryopreservation method of turbot spermatozoa has been recently established [5, 6]. Using Mounib 
extender supplemented with $10 \%$ dimethyl sulphoxide (DMSO) and $10 \%$ Bovine Serum Albumin (BSA) as a diluent, resulted in a $60-80 \%$ reactivation of the frozen-thawed spermatozoa. A $38 \%$ decrease of the adenosine triphosphate (ATP) content was recorded during the freezing process. However, mitochondrial respiratory activity was not altered, allowing a de novo ATP synthesis. Sperm velocity remained unchanged. Using 20000 spermatozoa $\cdot$ ovum $^{-1}$ resulted in the same fertilization rates with fresh or thawed sperm [6].

The aim of this work was to validate the cryopreservation method previously settled for turbot spermatozoa by checking the long term effects of sperm storage in frozen state on the hatching rate and larvae survival. Moreover, the viability of sperm samples stored during a 9 month period in liquid nitrogen was evaluated.

\section{MATERIAL AND METHODS}

Broodstock management, sperm and ova collection and cryopreservation process were previously described [6]. The percentage of motile spermatozoa was expressed as an arbitrary scale of 6 scores where 0 representing no motile spermatozoa, $1: 1-19 \%, 2$ : $20-39 \%, 3: 40-59 \%, 4: 60-79 \%$ and $5: 80-100 \%$ of spermatozoa showing progressive movement.

\subsection{Hatching and larval rearing performances}

Sperm collected from 4 males was frozen. According to the method previously proposed [21], triplicate batches of $3 \mathrm{~mL}$ ova (3 500 uva) selected from a good quality spawn (viability rate: $88.7 \%$, fertilization rate: $57.8 \pm 3.9 \%$ ) were inseminated using a non-discriminant ratio of 20000 fresh or thawed spermatozoa.ovum ${ }^{-1}$. After a contact time of 3 minutes between gametes, batches of eggs were randomly transferred in $1 \mathrm{~L}$ cylindroconical incubators. Water $\left(3 \mathrm{~L} \cdot \mathrm{h}^{-1}, 13^{\circ} \mathrm{C}\right)$ and aeration were introduced at the bottom of the tank. The number of hatched larvae was exhaustively counted. Hatching rate was defined as the number of larvae divided by the number of eggs transferred to incubators. After hatching, 1000 larvae of lots stemmed from inseminations carried out using the sperm of only 3 from the 4 males previously sampled, were transferred to $150 \mathrm{~L}$ cylindroconical lanks. Lots were reared in triplicate (18 tanks, occupying all available larval rearing facilities) according to the larval scheme previously described [22]. Ten days after hatching, all larvae were counted. For each lot, the wet weight of 30 larvae was measured to the nearest microgramme.

\subsection{Effect of storage duration}

Motility at $10 \mathrm{~s}$ and $60 \mathrm{~s}$ post-activation and fertilization capacity of sperm samples collected from 6 males were estimated in triplicate as a control. Then, several aliquots of sperm samples were frozen. The motility and the fertilization capacity of frozenthawed sperm samples (discriminant ratio of 6000 spermatozod.ovum ${ }^{-1}$ ) were assessed at different times after freezing (just after freezing, 1, 5, 7 and 9 months).

\subsection{Statistical analysis}

Data are expressed as mean \pm SD. Fertilization, hatching and larval survival rates, were subjected to angular transformation. Successive motility and fertilization rates recorded using frozen-thawed sperm samples during a 9 month period were respectively cxpressed as motility recovery index (motility of frozen-thawed sperm/motility of control) and fertilization recovery index (fertilization rate of frozen-thawed sperm/fertilization rate of control). All data were compared using a two-way ANOVA.

\section{RESULTS AND DISCUSSION}

\subsection{Hatching and larval rearing performances}

No significant differences in the fertilization rate and hatching rate (table $I$ ) were observed between fresh and frozen-thawed spermatozoa. Similar to results reported in carp (Cyprinus carpio, [12]), the hatching rate of turbot eggs was not significantly different using fresh or cryopreserved sperm. Similar percentages of eyed-egg stage and hatching success were observed in northern pike [2] between fresh and frozen-thawed spermatozoa. Then, the hatching rate of African catfish (Heterobranchus longifilis) and percentage of abnormal larvae were similar whatever the sperm [14]. Attempts conducted in marine fish species lead to similar results (cod, Gadus morhua [13]; hirame, Paralychthis olivaceus [23]). Furthermore, the number of abnormal larvae of hirame was not significantly different irrespective of sperm treatment. In the yellowtail flounder (Pleuronectes ferrugineus), the percentage of deformed larvae was $8 \%$ using cryopreserved sperm and 14 $\%$ using fresh sperm [19].

The survival rate and wet weight (table I) of 10-day old turbot larvae were not significantly different when ova were inseminated with fresh or frozen-thawed spermatozoa. Similar to our results, survival and growth of 30-day old tilapia fry were not decreased

Table I. Fertilization rate, hatching rate, larval survival rate and larval weight recorded after artificial fertilization using fresh or frozenthawed spermatozoa (mean $\pm \mathrm{SD}$ ).

\begin{tabular}{lcc}
\hline & Fresh sperm & Frozen sperm \\
\hline Fertilization rate $(\%)$ & $57.8 \pm 7.7$ & $59.1 \pm 12.0$ \\
Hatching rate $(\%)$ & $440 \pm 7.8$ & $41.8 \pm 9.5$ \\
Larval survival rate $(\%)$ & $87.2 \pm 2.7$ & $82.9 \pm 4.5$ \\
Larval weight $(\mu \mathrm{g})$ & $661 \pm 40$ & $686 \pm 24$ \\
\hline & & Aquat. Living Resour. 11(1)(1998)
\end{tabular}




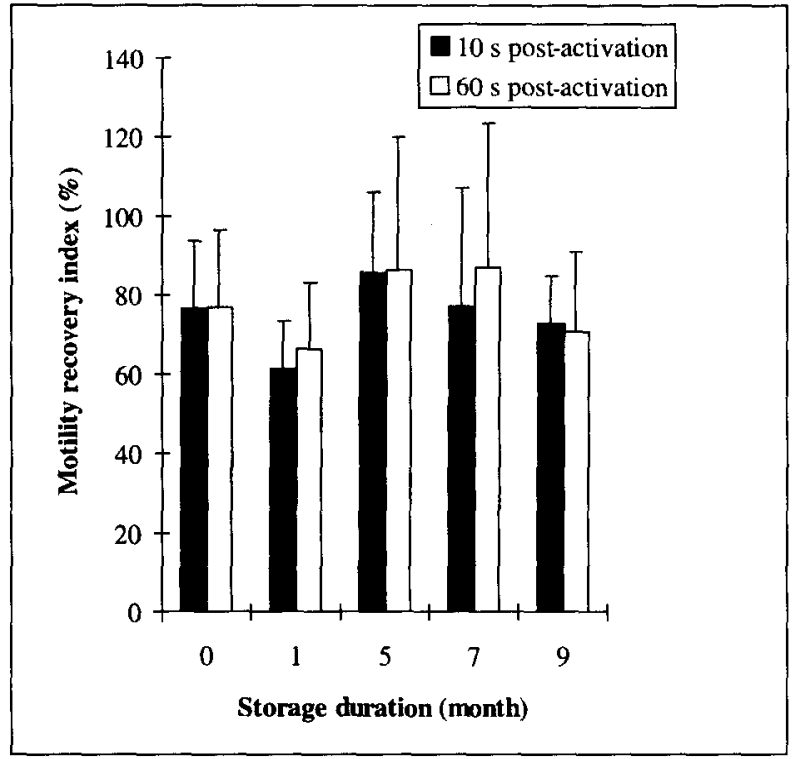

Figure 1. Motility recovery index recorded during a 9 month storage period at $10 \mathrm{~s}$ and $60 \mathrm{~s}$ post-activation.

using thawed spermatozoa [18]. Moreover, the growth of tilapias up to $800 \mathrm{~g} \mathrm{[4]} \mathrm{and} \mathrm{channel} \mathrm{catfish} \mathrm{up} \mathrm{to} 130$ $\mathrm{g}$ [24] were not altered using thawed spermatozoa during insemination practices.

\subsection{Effect of storage duration}

A 9 month storage period in liquid nitrogen did not significantly decrease the motility of turbot spermatozoa both recorded at $10 \mathrm{~s}$ and $60 \mathrm{~s}$ post-activation (figure 1) and their fertilization capacity (figure 2). Similar results were recorded in African catfish for a 8 month period [14], in carp for 12 month [10] and Artic charr (Salvelinus alpinus) for up to 3 years [15]. In marine fish species, the cryopreservation of plaice (Pleuronectes platessa) spermatozoa during a 315-day period resulted in fertilization and hatching rates very close to those assessed using fresh spermatozoa [16]. On the other hand, a decrease of the fertilization suc-

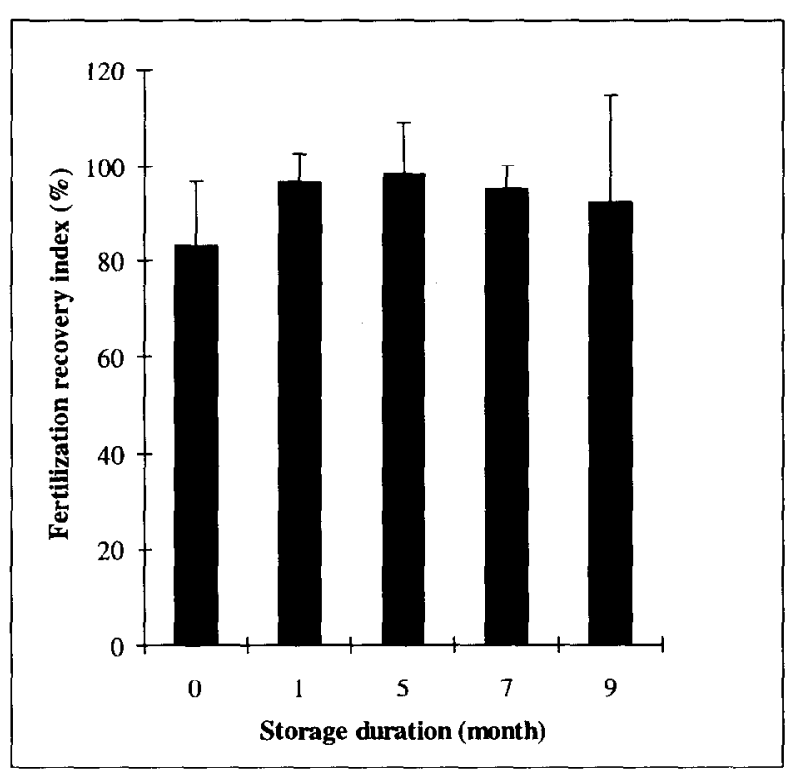

Figure 2. Fertilization recovery index recorded using a discriminant

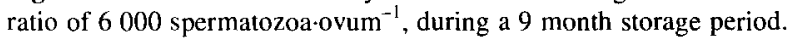

cess in relation to the storage duration period in liquid nitrogen is suggested in striped bass [9]. However, because of the limited number of observations the author admitted that further works were necessary to confirm this hypothesis.

The high quality of frozen-thawed turbot spermatozoa previously established using a set of bioassays such as percentage of motile spermatozoa, mitochondrial respiratory activity, velocity and fertilization capacity [6] is confirmed by the present results. In opposition to electron microscopic observations reported in rainbow trout $[3,11]$, this suggests an absence of genome alterations. Similarly, no effect of the freeze-thaw process was reported on the nucleus of Atlantic croaker (Micropogonias undulatus [7]) and marine puffer (Fugu niphobles [8]) spermatozoa. As a consequence, the cryopreservation technique of turbot spermatozoa can be used for routine operations.

\section{Acknowledgements}

We are grateful to N. Rossignol (IFREMER) for typing the text and V. Gautier (IFREMER) for literature research. 


\section{REFERENCES}

[1] Ashwood-Smith M.J., Low temperature preservation of cells, tissues and organs, in: Low temperature preservation in medecine and biology, Ashwodd-Smith M.J., Farrant J. (eds), Pitman Medical Ltd., Turnbridge Wells, 1980, pp. 19-44.

[2] Babiak I., Goglowski J., Luczynski M.J., Kucharczyk D., Luczynski M., Cryopreservation of the milt of the northern pike, J. Fish Biol. 46 (1995) 819-828.

[3] Billard R., Ultrastructure of trout spermatozoa: Changes after dilution and deep-freezing, Cell Tissue Res. 228 (1983) 205-218.

[4] Chao N.H., Chao W.C., Liu K.C., Liao I.C., The properties of tilapia sperm and its cryopreservation, J. Fish Biol. 30 (1987) 107-118.

[5] Chereguini O., Cal R.M., Dreanno C., Ogier de Baulny B., Suquet M., Maisse G., Short-term storage of turbot (Scophthalmus maximus) sperm, Aquat. Living Resour. 10 (1997) 251-255.

[6] Dreanno C., Suquet M., Quemener L., Cosson J., Fierville F., Normant Y., Billard R., Cryopreservation of turbot (Scophthalmus maximus) spermatozoa, Theriogenology 48 (1997) 589-603.

[7] Gwo J.C., Arnold C.R., Cryopreservation of Atlantic croaker spermatozoa: Evaluation of morphological changes, J. Exp. Zool. 264 (1992) 444-453.

[8] Gwo J.C., Kurokura H., Hirano R., Cryopreservation of spermatozoa from rainbow trout, common carp, and marine puffer, Nipon Suisan Gakkaishi 59 (1993) 777782.

[9] Kerby J.H., Cryogenic preservation of sperm from striped bass, Trans. Am. Fish. Soc. 112 (1983) 86-94

[10] Kurokura H., Hirano R., Tomita M., Iwahashi M., Cryopreservation of carp sperm, Aquaculture 37 (1984) 267-273.

[11] Lahnsteiner F., Berger B., Weismann T., Patzner R., Changes in morphology, metabolism and fertilization capacity of rainbow trout semen following cryopreservation, Progress. Fish Cult. 58 (1996) 149-159.

[12] Magyary I., Urbanyi B., Horvath L., Cryopreservation of common carp (Cyprinus carpio L.) sperm II. Optimal conditions for fertilization, J. Appl. Ichthyol. 12 (1996) 117-119.
[13] Mounib M.S., Cryogenic preservation of fish and mamalian spermatozoa, J. Reprod. Fert. 53 (1978) 13-18.

[14] Otémé Z.J., Nunez Rodriguez J., Kouassi C.K., Hem S., Agnèse J.F., Testicular structure, spermatogenesis and sperm cryopreservation in the African clariid catfish Heterobranchus longifilis (Valenciennes, 1840), Aquac. Res. 27 (1996) 805-813.

[15] Piironen J., Factors affecting fertilization rate with cryopreserved sperm of whitefish (Coregonus pallas), Aquaculture 66 (1987) 347-357.

[16] Pullin R.S.V., The storage of plaice (Pleuronectes platessa) sperm at low temperatures, Aquaculture 1 (1972) 279-283.

[17] Rana K.J., Cryopreservation of aquatic gametes and embryos: recent advances and applications, in: Proc. $5^{\text {th }}$ Int. Symp. Reproductive Physiology of Fish, Goetz F.W., Thomas P. (eds), Austin, Texas, U.S.A., 2-8 July 1995, 1995, pp. 85-89.

[18] Rana K.J., McAndrew B.J., The viability of cryopreserved tilapia spermatozoa, Aquaculture 76 (1989) 335-345.

[19] Richardson G.F., Crim L.W., Yao Z., Short C., Cryopreservation of yellowtail flounder (Pleuronectes ferrugineus) semen, in: Proc. $5^{\text {th }}$ Int. Symp. Reproductive Physiology of Fish, Goetz F.W., Thomas P. (eds), Austin, Texas, U.S.A., 2-8 July 1995, 1995, 136 p.

[20] Stoss J., Holtz W., Cryopreservation of rainbow trout (Salmo gairdneri) sperm I. Effects of thawing solution, sperm density and interval between thawing and insemination, Aquaculture 22 (1981) 97-104.

[21] Suquet M., Gaignon J.L., Quemener L., Normant Y., Artificial insemination of turbot (Scophthalmus maximus) eggs: a procedure for experimental purposes, in: Larvi' 95, Lavens P., Jaspers E., Roelants I. (eds), European Aquaculture Society 24 (1995) 57-59.

[22] Suquet M., Petton B., Normant Y., Dosdat A., Gaignon J.L., First rearing attempts of pollack, Pollachius pollachius, Aquat. Living Resour. 9 (1996) 103-106.

[23] Tabata K., Mizuta A., Cryopreservation of sex reversed gynogenetic female sperm in hirame, Fish. Sci. 63 (1997) 482-483.

[24] Tiersch T.R., Goudie C.A., Carmichael G.J., Cryopreservation of channel catfish sperm: Storage in cryoprotectants, fertilization trials, and growth of channel catfish produced with cryopreserved sperm, Trans. Am. Fish. Soc. 123 (1994) 580-586. 